\title{
Integrated analysis of gene expression and copy number variations in MET proto-oncogene-transformed human primary osteoblasts
}

\author{
RU-JIANG JIA* , CHUN-GEN LAN* ${ }^{*}$ XIU-CHAO WANG and CHUN-TAO GAO \\ Department of Pancreatic Cancer, Key Laboratory of Cancer Prevention and Therapy, National Clinical Research \\ Center for Cancer, Tianjin Medical University Cancer Institute and Hospital, Tianjin 300060, P.R. China
}

Received August 29, 2017; Accepted October 30, 2017

DOI: $10.3892 / \mathrm{mmr} .2017 .8135$

\begin{abstract}
The aim of the present study was to screen the potential osteosarcoma (OS)-associated genes and to obtain additional insight into the pathogenesis of OS. Transcriptional profile (ID: GSE28256) and copy number variations (CNV) profile were downloaded from Gene Expression Omnibus database. Differentially expressed genes (DEGs) between MET proto-oncogene-transformed human primary osteoblast (MET-HOB) samples and the control samples were identified using the Linear Models for Microarray Data package. Subsequently, CNV areas and CNVs were identified using cut-off criterion of $>30 \%$-overlap within the cases using detect_cnv.pl in PennCNV. Genes shared in DEGs and CNVs were obtained and discussed. Additionally, the Database for Annotation, Visualization and Integrated Discovery was used to identify significant Gene Ontology (GO) functions and pathways in DEGs with $\mathrm{P}<0.05$. A total of $1,601 \mathrm{DEG}$ were screened out in MET-HOBs and compared with control samples, including 784 upregulated genes, such as E2F transcription factor 1 (E2F1) and 2 (E2F2) and 817 downregulated genes, such as retinoblastoma $1(R B 1)$ and cyclin D1 $(C C N D 1)$. DEGs were enriched in 344 GO terms, such as extracellular region part and extracellular matrix and 14 pathways, including pathways in cancer and extracellular matrix-receptor interaction. Additionally, 239 duplications and 439 deletions in 678 genes from 1,313 chromosome regions were detected. A total of 12 genes were identified to be $\mathrm{CNV}$-driven genes, including cadherin 18, laminin subunit $\alpha 1$, spectrin $\beta$, erythrocytic, ciliary rootlet coiled-coil, rootletin pseudogene $2, \beta-1,4-\mathrm{N}$-acetyl-galactosaminyltransferase $1, \mathrm{G}$ protein regulated inducer of neurite outgrowth $1, \mathrm{EH}$
\end{abstract}

Correspondence to: Dr Chun-Tao Gao, Department of Pancreatic Cancer, Key Laboratory of Cancer Prevention and Therapy, National Clinical Research Center for Cancer, Tianjin Medical University Cancer Institute and Hospital, 22 West Huanhu Road, Hexi, Tianjin 300060, P.R. China

E-mail: gaochuntao@tjmuch.com

*Contributed equally

Key words: osteosarcoma, integrated analysis, differentially expressed genes, microarray data, upregulated, downregulated domain binding protein 1-like 1, growth factor independent 1, cathepsin Z, WNK lysine deficient protein kinase 1, glutathione S-transferase mu 2 and microsomal glutathione S-transferase 1. Therefore, cell cycle-associated genes including $E 2 F 1, E 2 F 2$, $R B 1$ and $C C N D 1$, and cell adhesion-associated genes, such as CDH18 and LAMA1 may be used as diagnosis and/or therapeutic markers for patients with OS.

\section{Introduction}

Osteosarcoma (OS), also termed bone sarcoma, originates from bone and particularly from the mesenchymal stem cell lineage (1). OS, the most common bone tumor, is highly aggressive and usually has poor prognosis (2). Additionally, OS primarily affects adolescents and children and $\sim 60 \%$ of neoplasms occur in patients under the age of $20(3,4)$. Current treatment frequently involves a combination of surgery and chemotherapy; however, OS still leads to a high mortality and morbidity, particularly in children and adolescents (1).

Currently, considerable progress has been made in identifying the critical factors in the development and progression of OS, including genes, pathways and copy number variants (CNVs) (5). Alterations of tumor suppressor gene expression including protein kinase, cAMP-dependent, regulatory, and type I a and deregulation of major signaling pathways such as the wingless-type MMTV integration site family, transforming growth factor- $\beta$, Notch and sonic hedgehog have been previously associated with OS $(6,7)$. It has also been previously demonstrated that OS development is dependent on loss of P53 and enhanced by loss of retinoblastoma 1 (RB1) (8). CNVs are DNA segments $1 \mathrm{~kb}$ in length which are present in a variable population frequency in the genome (9). During the 1990s, CNVs with duplications and deletions were expressed as an inducement of a quantity of single gene disorders (10). Various differentially expressed genes (DEGs) and several candidate CNVs in OS have been identified to be involved in the development of OS by analyzing the microarray data and high-resolution single nucleotide polymorphism (SNP)/CNV arrays $(11,12)$. However, frequently only one of these approaches has been used in previous studies to identify the candidate molecule, and the molecular mechanism of OS remains to be elucidated (9-11).

The proto-oncogene MET protein, a hepatocyte growth factor receptor, encodes tyrosine-kinase activity (13), which 
has been revealed to be aberrantly expressed in OS and closely associated with cancer (14-16). Therefore, overexpression of the MET oncogene may convert human primary osteoblasts (HOB) into OS cells.

The present study extracted the transcriptional and $\mathrm{CNV}$ profiles from Gene Expression Omnibus (GEO) database. The differentially expressed genes (DEGs) and CNVs were screened in the transcriptional profile of MET-HOB cells, which were previously turned into OS cells by lentiviral vector (LV)-driven overexpression of the MET oncogene. Subsequently, the shared genes in the expression and CNV profiles were analyzed. The present study obtained a series of candidate markers in OS and may provide the foundation for treatment of OS.

\section{Materials and methods}

Microarray and $C N V$ data. Transcriptional profile (ID: GSE28256) was downloaded from the GEO database (www.ncbi.nlm.nih.gov/geo/) which was based on the platform of GPL6098 (Illumina humanRef-8 v1.0 expression beadchip) (17). The dataset contained 15 samples, including $6 \mathrm{HOB}$ cell lines and 9 MET-HOBs clones, which were previously turned into osteosarcoma cells by over-expression of MET oncogene driven by a LV. The CNV data were extracted from the GSE32964 dataset in the GEO database, which included 36 samples for detecting SNP and 32 samples for CNV. A total of $32 \mathrm{CNV}$ samples of OS tumor tissues based on the platform of GPL6985 (Illumina HumanCNV370-QuadV3 DNA Analysis BeadChip) were analyzed in the present study.

Data preprocessing. The probe-level data of the transcriptional profile were initially converted into expression values. Probes that mapped with the gene names labeled in the annotation platform were transformed using $\log _{2}$ and normalized using preprocess-Core package in $\mathrm{R}$ version 2.9.0. According to the annotation platform, the values of probes corresponding to the same transcript were averaged and then defined as the final expression value of a transcript. The PennCNV tool (version 2014 May 07; http://pennenv.openbioinformatics.org) was used in the subsequent processing of data, the profile of $\mathrm{CNV}$ samples was converted into specific format for PennCNV, which contained $\log$ R Ratio: LRR and B Allele frequency: BAF. In addition, to investigate the differences among samples, a heatmap was generated to compare their expression values using the Gplots package in $\mathrm{R}$.

Identification of DEGs and CNV. A Student's t-test was conducted on the gene expression values between testing and control samples. The Linear Models for Microarray Data (LIMMA) package was used to normalize the data and identify the DEGs in MET-HOB samples compared with control samples using cut-offs of $\mathrm{P}<0.05$ and $\log _{2}$ fold-change (FC) $\mid>2$. Additionally, detect_cnv.pl in PennCNV was applied to select $\mathrm{CNV}$ areas and CNVs were identified with the cut-off criteria of $>30 \%$ overlap within the cases. Genes shared in $\mathrm{CNVs}$ and DEGs were identified as critical genes associated with the development of OS.

Functional enrichment of DEGs. The Database for Annotation, Visualization and Integrated Discovery (DAVID) provides
A

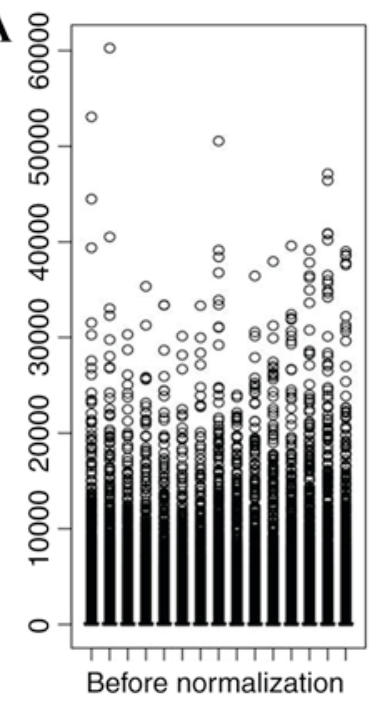

B

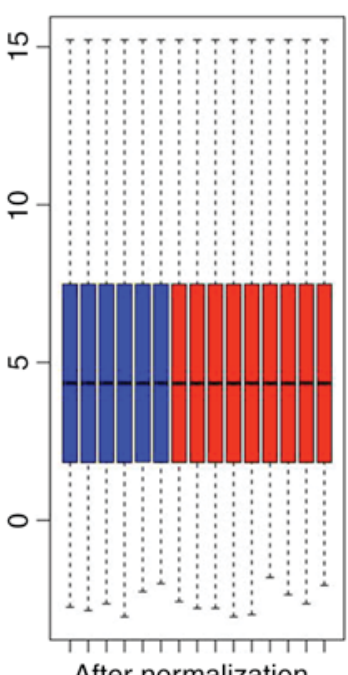

After normalization

Figure 1. Boxplots for genes in all samples (A) before and (B) after normalization. Red indicates MET proto-oncogene-transformed HOB samples and blue boxes indicate $\mathrm{HOB}$ samples. HOB, human primary osteoblasts.

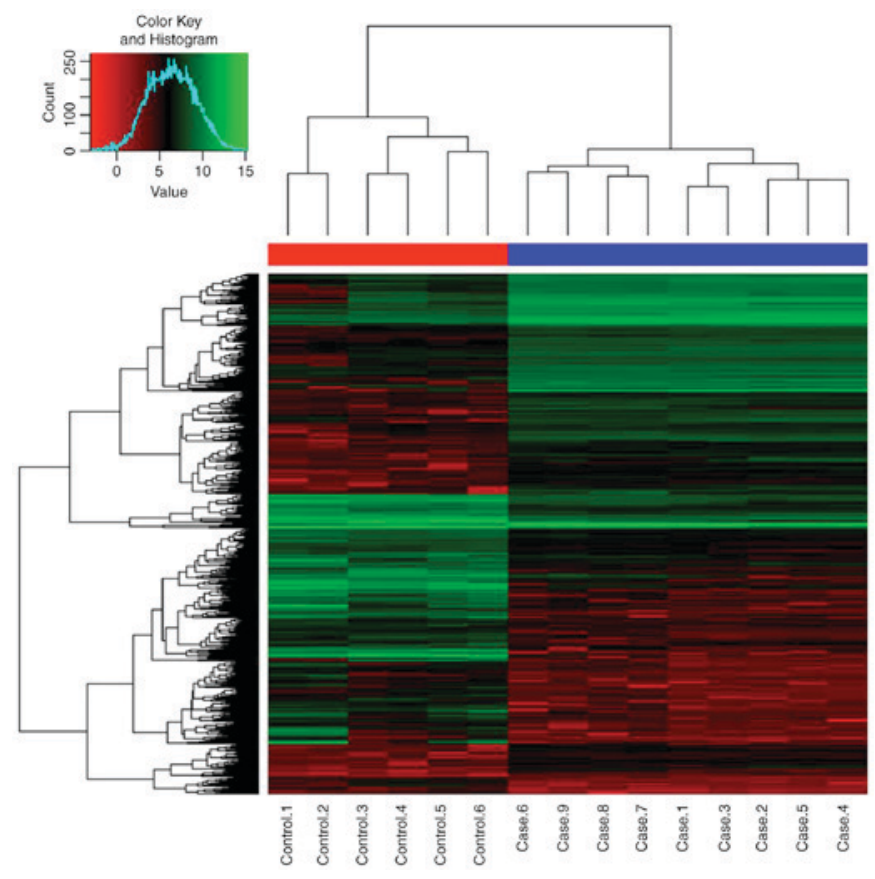

Figure 2. Hierarchical cluster analysis for the differentially expressed genes in MET-HOB and HOB samples. Cases 1-9 indicate MET-HOB samples and control 1-6 represent HOB samples. The gradual color change from green to red represents the changing process from upregulation to downregulation. HOB, human primary osteoblasts; MET-HOB, MET proto-oncogene-transformed human primary osteoblasts.

numerous comprehensive functional annotation which contributes to the understanding of the biological meanings behind abundant genes (18). Gene Ontology (GO) and the Kyoto Encyclopedia of Genes and Genomes (KEGG) analyses have become commonly used approaches for functional and pathway studies of large-scale genomic or transcription data, respectively (19). Therefore, they were used in the present study. Next, DAVID was used to screen the enriched GO terms and KEGG pathways in the DEGs. $\mathrm{P}<0.05$ was used as a cut-off criterion. 
Table I. The top $10 \%$ enriched GO terms for DEGs.

\begin{tabular}{|c|c|c|c|c|}
\hline Category & GO ID & GO name & Gene number & P-value \\
\hline $\mathrm{CC}$ & GO:0044421 & Extracellular region part & 134 & $2.68 \times 10^{-24}$ \\
\hline $\mathrm{CC}$ & GO:0031012 & Extracellular matrix & 74 & $4.08 \times 10^{-24}$ \\
\hline $\mathrm{CC}$ & GO:0005578 & Proteinaceous extracellular matrix & 71 & $4.79 \times 10^{-24}$ \\
\hline $\mathrm{BP}$ & GO:0001501 & Skeletal system development & 60 & $4.57 \times 10^{-15}$ \\
\hline MF & GO:0019838 & Growth factor binding & 32 & $2.32 \times 10^{-14}$ \\
\hline $\mathrm{BP}$ & GO:0001944 & Vasculature development & 50 & $1.22 \times 10^{-13}$ \\
\hline $\mathrm{BP}$ & GO:0001568 & Blood vessel development & 49 & $1.88 \times 10^{-13}$ \\
\hline $\mathrm{MF}$ & GO:0005201 & Extracellular matrix structural constituent & 28 & $2.11 \times 10^{-13}$ \\
\hline $\mathrm{BP}$ & GO:0042127 & Regulation of cell proliferation & 98 & $4.21 \times 10^{-12}$ \\
\hline $\mathrm{BP}$ & GO:0006260 & DNA replication & 40 & $8.03 \times 10^{-12}$ \\
\hline $\mathrm{BP}$ & GO:0007049 & Cell cycle & 96 & $1.09 \times 10^{-11}$ \\
\hline $\mathrm{BP}$ & GO:0051726 & Regulation of cell cycle & 55 & $1.23 \times 10^{-11}$ \\
\hline $\mathrm{BP}$ & GO:0022403 & Cell cycle phase & 63 & $1.57 \times 10^{-11}$ \\
\hline $\mathrm{CC}$ & GO:0005576 & Extracellular region & 179 & $1.87 \times 10^{-11}$ \\
\hline $\mathrm{CC}$ & GO:0044427 & Chromosomal part & 57 & $2.60 \times 10^{-11}$ \\
\hline $\mathrm{BP}$ & GO:0051270 & Regulation of cell motion & 39 & $5.52 \times 10^{-11}$ \\
\hline $\mathrm{BP}$ & GO:0006259 & DNA metabolic process & 70 & $8.61 \times 10^{-11}$ \\
\hline $\mathrm{CC}$ & GO:0044420 & Extracellular matrix part & 28 & $1.55 \times 10^{-10}$ \\
\hline $\mathrm{BP}$ & GO:0040012 & Regulation of locomotion & 38 & $1.89 \times 10^{-10}$ \\
\hline $\mathrm{BP}$ & GO:0051301 & Cell division & 49 & $1.93 \times 10^{-10}$ \\
\hline $\mathrm{BP}$ & GO:0030334 & Regulation of cell migration & 35 & $3.13 \times 10^{-10}$ \\
\hline $\mathrm{BP}$ & GO:0007155 & Rell adhesion & 85 & $5.11 \times 10^{-10}$ \\
\hline BP & GO:0022610 & Biological adhesion & 85 & $5.66 \times 10^{-10}$ \\
\hline $\mathrm{CC}$ & GO:0005615 & Extracellular space & 79 & $6.44 \times 10^{-10}$ \\
\hline $\mathrm{BP}$ & GO:0006928 & Cell motion & 65 & $6.97 \times 10^{-10}$ \\
\hline $\mathrm{BP}$ & GO:0022402 & Cell cycle process & 73 & $7.17 \times 10^{-10}$ \\
\hline $\mathrm{CC}$ & GO:0005694 & Chromosome & 60 & $1.09 \times 10^{-9}$ \\
\hline $\mathrm{BP}$ & GO:0000278 & Mitotic cell cycle & 54 & $2.53 \times 10^{-9}$ \\
\hline $\mathrm{BP}$ & GO:0000279 & M phase & 49 & $7.98 \times 10^{-9}$ \\
\hline $\mathrm{BP}$ & GO:0048514 & Blood vessel morphogenesis & 37 & $1.03 \times 10^{-8}$ \\
\hline $\mathrm{BP}$ & GO:0065004 & Protein-DNA complex assembly & 23 & $1.29 \times 10^{-8}$ \\
\hline $\mathrm{CC}$ & GO:0005581 & Collagen & 14 & $1.97 \times 10^{-8}$ \\
\hline $\mathrm{BP}$ & GO:0030198 & Extracellular matrix organization & 24 & $3.69 \times 10^{-8}$ \\
\hline $\mathrm{BP}$ & GO:0008283 & Cell proliferation & 57 & $4.64 \times 10^{-8}$ \\
\hline
\end{tabular}

GO, Gene Ontology; DEGs, differentially expressed genes; CC, cellular component; MF, molecular function; BP, biological process.

\section{Results}

Data preprocessing and DEGs screening. In the present study, 24,350 probes were detected in the original data and 21,454 non-redundant genes were obtained following data preprocessing. The raw data in all samples have been normalized (Fig. 1). A total of 1601 DEGs were screened out in MET-HOBs compared with controls. Among these genes, 784 were upregulated in MET-HOBs and 817 were downregulated. The hierarchical clustering analysis revealed a clearly distinct expression of all DEGs between MET-HOBs and HOBs (Fig. 2).

Function enrichment of DEGs. In order to identify the functions of the DEGs, they were performed GO $(\mathrm{P}<0.01)$ and
KEGG $(\mathrm{P}<0.01)$ enrichment analyses. The results indicated that $344 \mathrm{GO}$ terms were obtained and the top $10 \%$ terms were listed in Table I, such as extracellular region $(\mathrm{P}=2.68 \mathrm{E}-24)$, extracellular matrix (ECM; $\mathrm{P}=4.08 \mathrm{E}-24)$ and proteinaceous extracellular matrix $(\mathrm{P}=4.79 \mathrm{E}-24)$. Besides, 14 KEGG pathways were obtained and most of them were related to cancers, such as hsa05200: pathways in cancer $(\mathrm{P}=4$.12E-09), hsa04512: ECM-receptor interaction $(\mathrm{P}=2.41 \mathrm{E}-08)$ and hsa05222: small cell lung cancer $(\mathrm{P}=1.06 \mathrm{E}-05$; Table II).

Identification of $C N V s$. A total of 1,313 chromosome regions were identified and 678 genes (239 duplications and 439 deletions) were obtained, which were spread among 22 pairs of autosomes (Fig. 3). Then these CNVs were checked for 
overlap with the DEGs. Finally, 12 genes were identified in both in CNVs and DEGs, including the six upregulated genes cadherin 18 (CDH18), spectrin $\beta$, erythrocytic (SPTB), ciliary rootlet coiled-coil, rootletin pseudogene 2 (CROCCP2), $\beta-1,4-$ $\mathrm{N}$-acetyl-galactosaminyltransferase 1 (B4GALNT), G protein regulated inducer of neurite outgrowth 1 (GPRINI) and growth factor independent 1 (GFII). A total of six downregulated genes were identified, including laminin subunit $\alpha 1$ (LAMA1), EH domain binding protein 1-like 1 (EHBPIL1), cathepsin Z (CTSZ), WNK lysine deficient protein kinase 1 (PRKWNK1), glutathione S-transferase $\mu 2$ (GSTM2) and microsomal glutathione S-transferase 1 (MGSTI) (Table III).

\section{Discussion}

OS is a universally fatal disease, due to the rapid growth, high local aggressiveness, and metastasizing potential (20). Numerous DEGs and regulatory relationships between transcription factors and DEGs in OS have been identified using microarray data (12). Additionally, susceptibility genes associated with OS were also reported by analyzing SNP/CNV arrays (11). However, the underlying molecular mechanism of OS remains to be elucidated. In the present study, 1,601 DEGs were identified, including 784 upregulated and 817 downregulated DEGs and CNVs in 678 genes (239 duplications and 439 deletions) were observed in MET-HOBs samples when compared with controls. By analyzing the transcriptional profile and SNP/CNV arrays, CDH18, LAMA1, SPTB, CROCCP2, B4GALNT, GPRIN1, GFI1, EHBPIL1, CTSZ, PRKWNK1, GSTM2 and MGST1 were identified as CNV-driven DEGs.

The DEGs obtained in the current study suggested that several genes such as E2F transcription factor $1(E 2 F 1)$ and 2 $(E 2 F 2)$, retinoblastoma $1(R B 1)$ and cyclin D1 $(C C N D 1)$ were involved in various pathways. $E 2 F 1$ and $E 2 F 2$, members of the E2F family of transcription factors, were upregulated in the MET-HOBs samples. E2F proteins regulate the transcription of genes required for DNA synthesis (21). The E2F family has an important role in cell cycle regulation and action of tumor suppressor proteins, and is also a target of the transforming proteins of small DNA tumor viruses $(22,23)$. Additionally, the $\mathrm{RB}$ protein has been previously identified to bind to $\mathrm{E} 2 \mathrm{~F}$ transcription factors (24). It is evident that the RB/E2F pathway is very important in regulating the initiation of DNA replication and the pathway is disrupted in the majority of human cancers (25). CCND1, is part of the highly conserved cyclin family, is a nuclear protein required for cell cycle progression in G1 phase (26). It has been previously reported that CCND1 has an important role in the regulation of OS cell proliferation (26). Consistently, the findings of the present study revealed that those genes were involved in several cell cycle-associated GO terms, such as cell cycle, cell cycle phase, regulation of cell cycle and cell division, and cancer-associated KEGG pathways, including pathways in cancer, small cell lung cancer and melanoma. Therefore, the present study is reliable and may suggest that the screened DEGs such as E2F1,E2F2, $R B 1$ and $C C N D 1$ are closely associated with the cell cycle and cell division of OS.

CNVs such as deletions, duplications and amplifications across the whole genome may contribute to OS
Table II. Enriched Kyoto Encyclopedia of Genes and Genomes pathways for DEGs.

\begin{tabular}{llcl}
\hline KEGG ID & \multicolumn{1}{c}{ Pathway name } & $\begin{array}{c}\text { Gene } \\
\text { number }\end{array}$ & P-value \\
\hline hsa05200 & Pathways in cancer & 53 & $4.12 \times 10^{-9}$ \\
hsa04512 & ECM-receptor interaction & 23 & $2.41 \times 10^{-8}$ \\
hsa05222 & Small cell lung cancer & 19 & $1.06 \times 10^{-5}$ \\
hsa03030 & DNA replication & 12 & $1.72 \times 10^{-5}$ \\
hsa04510 & Focal adhesion & 30 & $8.78 \times 10^{-5}$ \\
hsa04115 & p53 signaling pathway & 15 & $1.62 \times 10^{-4}$ \\
hsa05210 & Colorectal cancer & 16 & $4.93 \times 10^{-4}$ \\
hsa05218 & Melanoma & 14 & $9.09 \times 10^{-4}$ \\
hsa05219 & Bladder cancer & 10 & $1.79 \times 10^{-3}$ \\
hsa00980 & Metabolism of xenobiotics & 12 & $2.20 \times 10^{-3}$ \\
& by cytochrome P450 & & \\
hsa05215 & Prostate cancer & 15 & $2.68 \times 10^{-3}$ \\
hsa05217 & Basal cell carcinoma & 11 & $3.69 \times 10^{-3}$ \\
hsa05214 & Glioma & 11 & $9.89 \times 10^{-3}$ \\
\hline
\end{tabular}

DEGs, differentially expressed genes.

Table III. CNV-driven genes.

\begin{tabular}{lc}
\hline Gene & $\operatorname{logFC}$ \\
\hline LAMA1 & -2.583 \\
EHBPIL1 & -5.75702 \\
SPTB & 5.224308 \\
CTSZ & -7.39063 \\
CROCCP2 & 2.491733 \\
B4GALNT & 3.6299 \\
CDH18 & 2.227242 \\
GPRIN1 & 2.361558 \\
PRKWNK1 & -2.75581 \\
GFI1 & 3.577933 \\
GSTM2 & -2.62289 \\
MGST1 & -2.30508 \\
\hline
\end{tabular}

$\mathrm{CNV}$, copy number variations; FC, fold-change.

tumorigenesis (27). It is of note that CNVs in cyclin-dependent kinase inhibitor 2A (CDKN2A), sex determining region Y-box 6 (SOX6) and phosphatase and tensin homolog (PTEN) were associated with Ewing sarcoma (28). The trail of $C D K N 2 A / B$ locus was detected in OS cell lines (29), whereas two SNPs in the SOX6 gene were identified to be associated with both hip bone mineral density and body mass index in Caucasians (30). In addition, copy number losses in PTEN were common events in OS (31). In the present study, further analysis identified $12 \mathrm{CNV}$-driven genes in MET-HOBs samples, such as $\mathrm{CDH} 18$ (upregulated) and LAMAl (downregulated), which were associated with cell adhesion. Since the 1990s, many cadherins and cadherin-associated proteins 

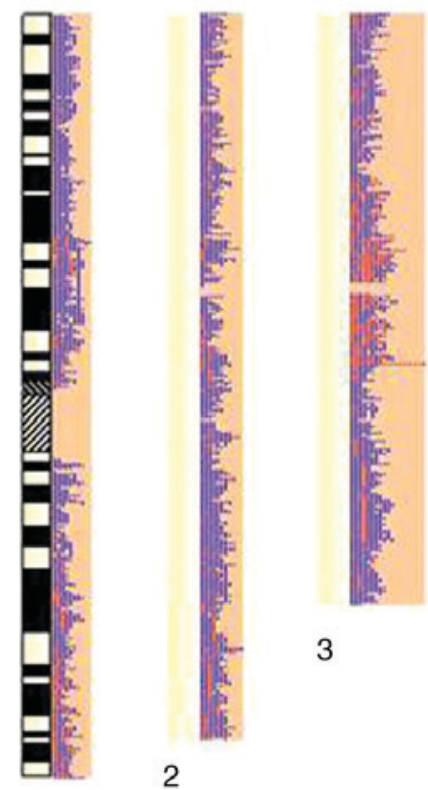

3

4

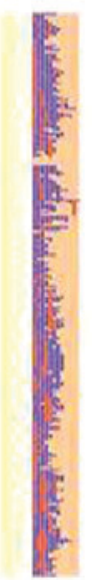

5
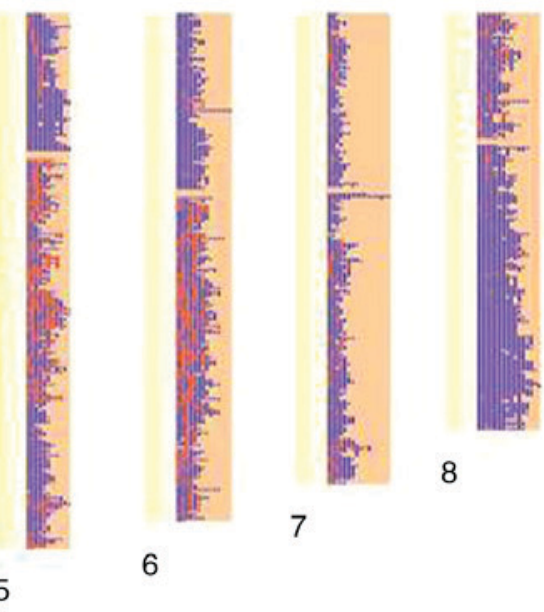

8

7

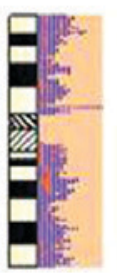

16

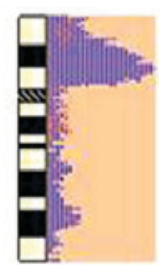

17

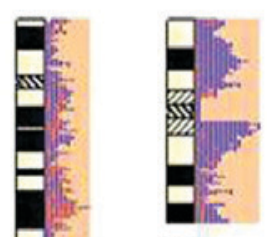

19
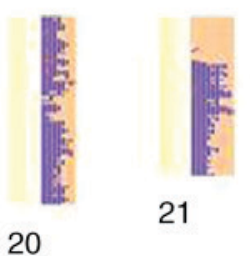

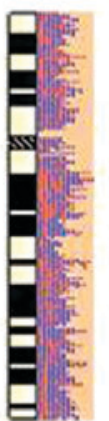

10

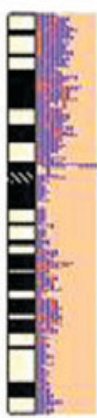

11

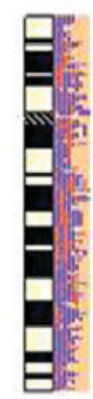

12
18
15

14

Figure 3. Genome distributions of CNVs in MET proto-oncogene-transformed human primary osteoblast samples. The PennCNV tool was used to select CNV areas. CNVs were identified with the cut-off criteria of $>30 \%$ overlap within the dataset. Red represents deletion and purple represents duplication. CNVs, copy number variations.

had been identified and implicated in cancers as candidate tumor suppressors or proto-oncogenes (32). Deregulation of cadherin-catenin complexes may contribute to tumor development by influencing the adhesion of epithelial cells (33). CDH18 is a member of the cadherin superfamily that mediates calcium-dependent cell-cell adhesion (34). Although, no previous studies have not identified a direct association between $\mathrm{CDH} 18$ and OS, it has been revealed that an Exon 2 deletion of $\mathrm{CDH} 18$ may be associated with human colorectal cancer and $\mathrm{CDH} 18$ may act as novel candidate gene involved in colorectal cancer predisposition (35). In the current study, $\mathrm{CDH} 18$ was upregulated and $\mathrm{CNV}$ s were detected in $\mathrm{CDH} 18$ of MET-HOBs samples; therefore, $C D H 18$ may have a role in cell-cell adhesion of OS. Additionally, LAMA1, also termed EHS laminin, was downregulated in MET-HOBs samples when compared with controls. Laminin is a complex glycoprotein and is considered to control the attachment, migration and organization of cells during embryonic development by interacting with other ECM components $(36,37)$. Additionally, it has been previously reported that metadherin, as a laminin receptor, has an important role in controlling tumorigenesis and metastasis in many human cancers (38-40). Metadherin, a type II membrane protein in OS cells, may enhance cell invasion by regulating cell adhesion to the ECM through interaction with laminin (41). Therefore, LAMAl may be involved in cell adhesion and cell-cell interactions in OS.

It is of note that there were some limitations in the present study. Only the OS-associated CNVs and DEGs were identified, whereas the transcription factors and protein-protein interaction network remain to be determined. The current findings were obtained by bioinformatics analysis and the corresponding validations were not performed. Therefore, future studies should involve in performing experiments such as reverse transcription-quantitative polymerase reaction and western blotting to validate the CNVs and DEGs identified.

In conclusion, a series of DEGs were identified to be associated with cell cycle and cell division of human OS, specifically $E 2 F 1, E 2 F 2, R B 1$ and CCND1. Additionally, $12 \mathrm{CNV}$-driven DEGs were obtained and the cell adhesion-associated genes such as CDH18 and LAMA1 may contribute to OS cell-cell adhesion. These genes may act as alternative diagnosis and/or therapeutic markers for patients with OS. The present study developed the current understanding about the etiology of OS and provided the foundation for the development of novel treatment strategies for OS. However, further experiments are required to confirm these findings. 


\section{References}

1. Heymann D and Rédini F: Targeted therapies for bone sarcomas. Bonekey Rep 2: 378, 2013.

2. Jemal A, Siegel R, Xu J and Ward E: Cancer statistics, 2010. CA Cancer J Clin 60: 277-300, 2010.

3. Li C, Cheng Q, Liu J, Wang B, Chen D and Liu Y: Potent growth-inhibitory effect of TRAIL therapy mediated by double-regulated oncolytic adenovirus on osteosarcoma. Mol Cell Biochem 364: 337-344, 2012.

4. He JP, Hao Y, Wang XL, Yang XJ, Shao JF, Guo FJ and Feng JX: Review of the molecular pathogenesis of osteosarcoma. Asian Pac J Cancer Prev 15: 5967-5976, 2014.

5. Xiong Y, Wu S, Du Q, Wang A and Wang Z: Integrated analysis of gene expression and genomic aberration data in osteosarcoma (OS). Cancer Gene Ther 22: 524-529, 2015.

6. Molyneux SD, Di Grappa MA, Beristain AG, McKee TD, Wai DH, Paderova J, Kashyap M, Hu P, Maiuri T, Narala SR, et al: Prkarla is an osteosarcoma tumor suppressor that defines a molecular subclass in mice. J Clin Invest 120: 3310-3325, 2010.

7. Tang N, Song WX, Luo J, Haydon RC and He TC: Osteosarcoma development and stem cell differentiation. Clin Orthop Relat Res 466: 2114-2130, 2008.

8. Walkley CR, Qudsi R, Sankaran VG, Perry JA, Gostissa M, Roth SI, Rodda SJ, Snay E, Dunning P, Fahey FH, et al: Conditional mouse osteosarcoma, dependent on p53 loss and potentiated by loss of $\mathrm{Rb}$, mimics the human disease. Genes Dev 22: 1662-1676, 2008.

9. Kirov G, Rees E, Walters JT, Escott-Price V, Georgieva L, Richards AL, Chambert KD, Davies G, Legge SE, Moran JL, et al: The penetrance of copy number variations for schizophrenia and developmental delay. Biol Psychiatry 75: 378-385, 2014.

10. Riccardi VM and Lupski JR: Duplications, deletions, and single-nucleotide variations: The complexity of genetic arithmetic. Genet Med 15: 172-173, 2013.

11. Porat RM, Pasic I, Shlien A, Golgoz N, Andrulis I, Wunder JS and Malkin D: Genome-wide copy number analysis reveals two novel loci for susceptibility to sporadic osteosarcoma. Cancer Res 71 (8 Suppl): S5334, 2011.

12. Luo Y, Deng Z and Chen J: Pivotal regulatory network and genes in osteosarcoma. Arch Med Sci 9: 569-575, 2013.

13. MacEwen EG, Kutzke J, Carew J, Pastor J, Schmidt JA, Tsan R, Thamm DH and Radinsky R: c-Met tyrosine kinase receptor expression and function in human and canine osteosarcoma cells. Clin Exp Metastasis 20: 421-430, 2003.

14. Ferracini R, Angelini P, Cagliero E, Linari A, Martano M, Wunder J and Buracco P: MET oncogene aberrant expression in canine osteosarcoma. J Orthop Res 18: 253-256, 2000.

15. Coltella N, Manara MC, Cerisano V, Trusolino L, Di Renzo MF, Scotlandi K and Ferracini R: Role of the MET/HGF receptor in proliferation and invasive behavior of osteosarcoma. FASEB J 17: 1162-1164, 2003.

16. Naka T, Iwamoto Y, Shinohara N, Ushijima M, Chuman H and Tsuneyoshi M: Expression of c-met proto-oncogene product (c-MET) in benign and malignant bone tumors. Mod Pathol 10 832-838, 1997.

17. Dani N, Olivero M, Mareschi K, van Duist MM, Miretti S, Cuvertino S, Patanè S, Calogero R, Ferracini R, Scotlandi K, et al: The MET oncogene transforms human primary bone-derived cells into osteosarcomas by targeting committed osteo-progenitors. J Bone Miner Res 27: 1322-1334, 2012.

18. Huang DW, Sherman BT, Tan Q, Collins JR, Alvord WG, Roayaei J, Stephens R, Baseler MW, Lane HC and Lempicki RA: The DAVID gene functional classification tool: A novel biological module-centric algorithm to functionally analyze large gene lists. Genome Biol 8: R183, 2007.

19. Kanehisa M and Goto S: KEGG: Kyoto encyclopedia of genes and genomes. Nucleic Acids Res 28: 27-30, 2000.

20. Mohseny AB, Tieken C, van der Velden PA, Szuhai K, de Andrea C, Hogendoorn PC and Cleton-Jansen AM: Small deletions but not methylation underlie CDKN2A/p16 loss of expression in conventional osteosarcoma. Genes Chromosomes Cancer 49: 1095-1103, 2010.
21. Lim JH, Chang YC, Park YB, Park JW and Kwon TK: Transcriptional repression of E2F gene by proteasome inhibitors in human osteosarcoma cells. Biochem Biophys Res Commun 318: 868-872, 2004

22. Tsantoulis PK and Gorgoulis VG: Involvement of E2F transcription factor family in cancer. Eur J Cancer 41: 2403-2414, 2005.

23. Helt AM and Galloway DA: Mechanisms by which DNA tumor virus oncoproteins target the $\mathrm{Rb}$ family of pocket proteins. Carcinogenesis 24: 159-169, 2003.

24. Lees JA, Saito M, Vidal M, Valentine M, Look T, Harlow E, Dyson $\mathrm{N}$ and Helin K: The retinoblastoma protein binds to a family of E2F transcription factors. Mol Cell Biol 13: 7813-7825, 1993.

25. Nevins JR: The Rb/E2F pathway and cancer. Hum Mol Genet 10: 699-703, 2001.

26. Baldin V, Lukas J, Marcote MJ, Pagano M and Draetta G: Cyclin $\mathrm{D} 1$ is a nuclear protein required for cell cycle progression in G1. Genes Dev 7: 812-821, 1993.

27. Gokgoz N, Wunder JS and Andrulis IL: Genome-wide analysis of DNA copy number variations in osteosarcoma. Cancer Res 72 (8 Suppl): S5075, 2012.

28. Lynn M, Wang Y, Slater J, Shah N, Conroy J, Ennis S, Morris T, Betts DR, Fletcher JA and O'Sullivan MJ: High-resolution genome-wide copy-number analyses identify localized copy-number alterations in Ewing sarcoma. Diagn Mol Pathol 22: 76-84, 2013.

29. Ottaviano L, Schaefer KL, Gajewski M, Huckenbeck W, Baldus S, Rogel U, Mackintosh C, de Alava E, Myklebost O, Kresse SH, et al: Molecular characterization of commonly used cell lines for bone tumor research: A trans-European EuroBoNet effort. Genes Chromosomes Cancer 49: 40-51, 2010.

30. Liu YZ, Pei YF, Liu JF, Yang F, Guo Y, Zhang L, Liu XG, Yan H, Wang L, Zhang YP, et al: Powerful bivariate genome-wide association analyses suggest the SOX6 gene influencing both obesity and osteoporosis phenotypes in males. PLoS One 4: e6827, 2009.

31. Freeman SS, Allen SW, Ganti R, Wu J, Ma J, Su X, Neale G, Dome JS, Daw NC and Khoury JD: Copy number gains in EGFR and copy number losses in PTEN are common events in osteosarcoma tumors. Cancer 113: 1453-1461, 2008.

32. Berx G and Van Roy F: Involvement of members of the cadherin superfamily in cancer. Cold Spring Harb Perspect Biol 1: a003129, 2009.

33. Goss KH and Groden J: Biology of the adenomatous polyposis coli tumor suppressor. J Clin Oncol 18: 1967-1979, 2000.

34. Yagi T and Takeichi M: Cadherin superfamily genes: Functions, genomic organization, and neurologic diversity. Genes Dev 14: $1169-1180,2000$

35. Venkatachalam R, Verwiel ET, Kamping EJ, Hoenselaar E, Görgens H, Schackert HK, Van Krieken JH, Ligtenberg MJ, Hoogerbrugge N, van Kessel AG and Kuiper RP: Identification of candidate predisposing copy number variants in familial and early-onset colorectal cancer patients. Int J Cancer 129: 1635-1642, 2011.

36. Dziadek M: Role of laminin-nidogen complexes in basement membrane formation during embryonic development. Experientia 51: 901-913, 1995.

37. Kleinman HK, Cannon FB, Laurie GW, Hassell JR, Aumailley M, Terranova VP, Martin GR and DuBois-Dalcq M: Biological activities of laminin. J Cell Biochem 27: 317-325, 1985.

38. Li X, Kong X, Huo Q, Guo H, Yan S, Yuan C, Moran MS, Shao C and Yang Q: Metadherin enhances the invasiveness of breast cancer cells by inducing epithelial to mesenchymal transition. Cancer Sci 102: 1151-1157, 2011.

39. Zhu K, Dai Z, Pan Q, Wang Z, Yang GH, Yu L, Ding ZB, Shi GM, Ke AW, Yang XR, et al: Metadherin promotes hepatocellular carcinoma metastasis through induction of epithelial-mesenchymal transition. Clin Cancer Res 17: 7294-7302, 2011

40. Wei Y, Hu G and Kang Y: Metadherin as a link between metastasis and chemoresistance. Cell Cycle 8: 2132-2137, 2009.

41. Zhu L, Zhang P, Yang Y, Buford AS, Wang WL, Thomas DG and Hughes DP: Abstract A53: Metadherin functions as a laminin receptor that is essential for metastasis and is associated with poor survival in osteosarcoma. Cancer Res 74 (20 Suppl): A53, 2014. 